\title{
The impact of Human Choice and Computers and Technical Committee 9 on ICTs and Society: A critical sociotechnical tale
}

\author{
David Kreps ${ }^{1[0000-0002-5776-2888]}$ and Gordon Fletcher ${ }^{\text {[0000-0002-3294-0465] }}$ \\ ${ }^{1}$ National University of Ireland, Galway, Co. Galway, Ireland \\ ${ }^{2}$ University of Salford, Greater Manchester, UK \\ david.kreps@nuigalway.ie \\ g.fletcheresalford.ac.uk
}

\begin{abstract}
In this chapter we briefly recount the history of the Human Choice and Computers conference series, and of Technical Committee 9, and show that not only has there been a marked focus, over more than four decades, on a critical and sociotechnical approach to understanding the relationship between ICTs and society, but that HCC and TC9 might be regarded as the original and continuing home of the critical academic voice in ICT. We show this through a textual analysis of the proceedings of the conferences, and through biographical detail concerning the key players involved.
\end{abstract}

Keywords: critical, sociotechnical, IFIP TC9.

\section{Introduction}

What follows is a history of Technical Committee 9 and the Human Choice and Computers conference series, compiled by current TC9 Chair, David Kreps, and HCC12 Co-Chair Gordon Fletcher. To explore this history the authors refer to short histories compiled by predecessors, to obituaries, and to some of the texts published over the many years of TC9's activities. The authors have also used a textual analysis tool to examine the existing corpus of HCC texts, revealing some insightful details of the broader concerns of the many academics over time who have contributed to the activities of TC9.

What emerges from this history, and from the textual analysis, points clearly to TC9 and HCC being the original and continuing home of the critical academic voice in ICT, growing from the isolated thoughts of concerned engineers in the 1970s to the primary and most comprehensive forum where the full range of the concerns of the relationships of ICT and Society can be discussed with a critical perspective. 


\section{The history of HCC and TC9}

Fourteen years after the formation of IFIP, in 1974, the Human Choice and Computers (HCC) conference series - the biennial conference of Technical Committee 9 (TC9) began with its first gathering in Vienna. The conference was led by Heinz Zemanek, as the President of IFIP, with the proceedings published in the following year by Mumford and Sackman undertaking duties as the editors [30]. In this first conference, trade unionists, social scientists, and computer technologists all expressed their dismay at being reduced to mere tools of management. The participants notably included Fred Margulies who had foreshadowed much of this concern in a paper on trade unionism at the IFIP World Computer Congress in 1970 [26]. The overarching outcome was a concern over the way they felt people were being forced to use computers in dehumanizing ways. The consensus of the conference, and of Mumford and Sackman's subsequent summary chapter in the proceedings ('International Human Choice and Computers: Conference Retrospect and Prospect' [29]) was that sociotechnical problems, including the use of computer systems, must be solved in ways that include community, national, and especially workers' interests; that, ultimately, humanistic needs must take precedence over technological and economic considerations.

Since that first conference, the HCC series has firmly remained at the cutting edge of innovative and critical thinking about the interface between the social and technology (Figure 5). The central remit of IFIP's Technical Committee 9 - of which HCC is the flagship conference - is the relationship between computers and society. As Jacques Berleur, Magda Herschui and Lorenz Hilty related in their introduction to the Proceedings of HCC9, "The success of HCC1 was such that IFIP-TC9 henceforth considered it the TC's founding event, if not birthplace. TC9 was conceived in 1976, two years after HCC1." [9]

The founding chair of TC9 was Calvin C. Gotlieb (1976-1981). Gotlieb, (known as Kelly) was from the Department of Computer Science at the University of Toronto, Canada. In his keynote, entitled, 'Computers - A Gift of Fire,' to the IFIP Congress in 1980, he said: "As computer technology spreads globally, it begins to behave like other modern technologies in that undesirable side-effects appear. Much more serious than computer effects on privacy are the impacts of microprocessors on industrial employment. Another issue arises out of evidence presented by managers and social scientists that using computers in decision-making can lead to systems which are too rigid and, especially in government, to procedures which failed to meet human needs." [17]

From the outset, then, HCC and TC9 have been focused on the social impacts of computing and not merely the many interfaces that exist between computing and society. This more nuanced perspective also means that HCC and TC9 are among the first sources of sustained consideration of the ethical requirements on computing and information technology professionals. TC9's founding aims (only marginally revised in 2008 and 2009 to include reference to new Working Groups) were: 'To develop understanding of how ICT innovation is associated with change in society'; and 'To influence the shaping of socially responsible and ethical policies and professional practices.' These aims were given application through Gotlieb's legacy in the establishment of the 
Technical Committee's first two Working Groups, in 1977: WG9.1 on Computers and Work, and WG9.2 on Social Accountability and Computing.

After Gotlieb's six-year tenure ended, the TC9 journey faltered somewhat with two Chairs in two years. R. Brotherton (1982-1982) and Fred Margulies (1983-1983) remained in post only from one IFIP General Assembly to the next. Margulies did, however, manage to achieve a fair bit during his time at IFIP. As the Austrian Representative to IFIP, Margulies had supported Zemanek, the President of IBM Austria, to run the first HCC held in Vienna in 1974. He then helped Gottlieb organize HCC2 in Baden (Austria) in 1979 (June 4-8) [28].

With Harold Sackman (1984-1989) - co-editor of the HCC1 proceedings - in the Chair a new energy returned to TC9. Sackman staged HCC3 during September 1985 in Stockholm, Sweden. While a new chair had brought new stability to the committee it was a difficult period for the sociotechnical approach associated with TC9. The tension is evident and well-documented in the conference proceedings for HCC3 [36]. The very nature, scope and purpose of the relationship between technology and people were at the heart of an intensely critical and heated debate. In his introduction to the HCC3 proceedings, Sackman took the opportunity to remind an increasingly diverse readership of the ranked list of objectives for TC9 as:

1. Protection of Individual Rights

2. Employment and the Quality of Life

3. International Problem Solving

4. International Studies on Social Impacts

5. Professional Social Accountability

6. Universal Social Benefits

7. Protection of Group and Collective Rights

8. International Planning and Cooperation

9. International Education

To follow on from the challenges presented through the HCC 3 conference, Sackman determined to bring better understanding of ethical behavior to the computing profession. In 1988 he began a project "to create an IFIP code of ethics" [6]. This ethical flavor can be recognized in the HCC conferences as a continuing and upwardly trending theme, seen through the more recent conferences (after a decline in HCC7 and HCC8) (Figure 1). It was to be more than three decades before this project would come to realization. In the same year, Sackman established a new Working Group: WG9.3, with the theme of Home Oriented Informatics and Telematics (and now being reimagined and relaunched as 'Intelligent Communities'). This shift to broader social perspectives is hinted at with the corollary of a declining interest in terms related to professional* (Figure 2) across the HCC corpus. This declining interest was accelerated in HCC8 and HCC 9 with consciously positioned themes around wider viewpoints on the information society. 


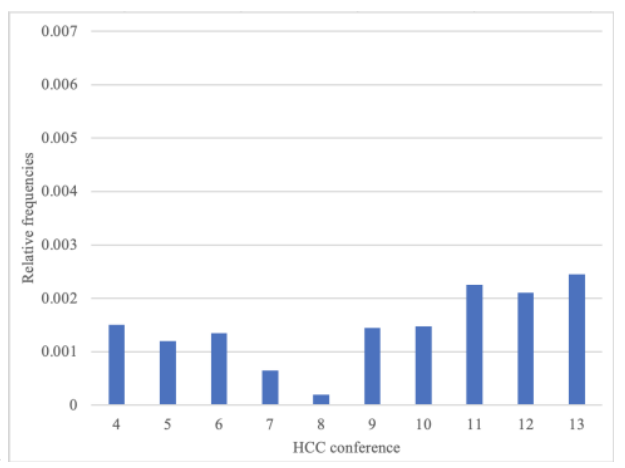

Fig. 1.

Fig 1. Frequency of 'ethic*' terms across the HCC corpus

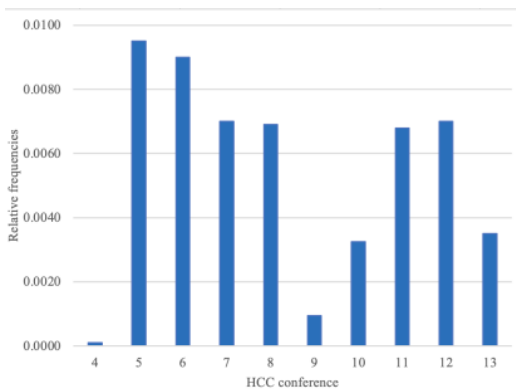

Fig. 2. Frequency of 'professional*' terms across the HCC corpus

The energy Sackman had put into TC9 and HCC was then built upon by Klaus Brunnstein (1990-1995), who staged HCC4 in July 1990, in Dublin. The proceedings were edited by Berleur and Drumm [7]. Brunnstein who, as early as 1973, had become "the first European professor for the application of Information Technology, concentrating on education" [38] later became a prominent champion of data security. He was one of the founder members of the Computer Anti-Virus Research Organization (CARO) [13]. As Tommi Uhlemann, from global security specialists ESET, said in his obituary in 2015, "In Germany he'll mostly be remembered for his fight for data protection in the 80's. He played a leading role in having new laws in this field" [38]. During his tenure, Brunnstein formally established Working Group 9.4 on ICTs in Developing Countries. This was a direct response to, and a championing of, Subash Bhatnagar's proposal at the General Assembly in 1989 [37,38], that followed the launch of the group at a conference in New Delhi in 1988 [11]. At the same time Working Group 9.5 was established with a focus on the social implications of artificial intelligence and virtual worlds.

Collecting together the full HCC4 proceedings reveals expected keywords but the influence of Brunnstein's own personal priorities can also be identified in these keywords (Figure 3). 'Privacy', 'ethics', 'ethical', 'environmental' and 'sustainable' are all visible but set against the wider perspective on the relationship between 'people' and 
'computing'. Keywords such as 'governance', 'process', 'infrastructure' and particularly 'power' indicate that the critical perspective can be found throughout the individual papers in the proceedings.

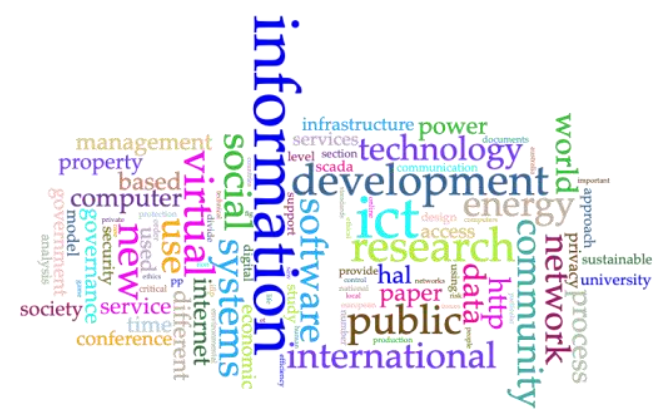

Fig. 3. HCC4 corpus keywords

Pertti Järvinen (1996-1998), who had been TC9 Secretary under Brunnstein, then assumed the chair of TC9 and oversaw delivery of HCC5 in August 1998, in Geneva, Switzerland. The proceedings were edited by Rasmussen, Beardon and Munari [33]. A principal component analysis of the full text of HCC5 reveals the correlation between keywords throughout the proceedings (Figure 4). The analysis extracts the most used terms and these are then placed closer together when they are more commonly used together. The rising importance of the Internet is an important outlier. 'Society' and 'public' strongly evidence another theme as is a cluster linking 'users', 'communication' and 'access' and a further set bringing together 'design', 'human', 'research' and 'university'. The presence of 'research', 'university' and 'conference' as persistent keywords seen across all HCC proceedings reflects levels of self-awareness and the conscious recognition that the researchers in HCC proceedings were in a position of privileged circumstances, looking in on the personal, social and organizational experience of computers and computing. The separation of 'people' and 'data' from other keywords points to their usage in many different contexts. There is a loose indication of the overarching theme for the majority of keywords and the way in which the theme of globalization in this conference was distilled by its contributors. 


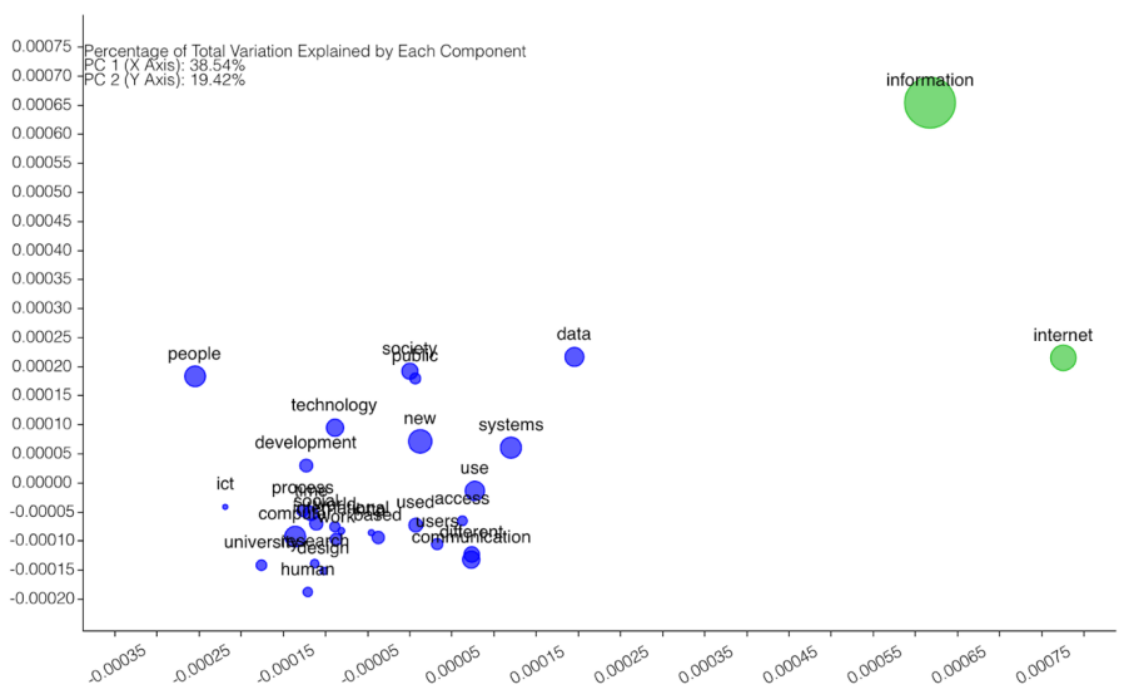

Fig. 4. Principal component analysis of the full text of the HCC5 proceedings

Jacques Berleur (TC9 Chair 1999-2004), a champion of WG9.2, previously an editor of the HCC4 proceedings and a paper contributor to HCC5, then became Chair of TC9 in 1999, with Chrisanthi Avgerou (WG9.4 Chair since 1996) as his Vice-Chair. Berleur oversaw HCC6 as part of the World Computer Congress in 2002, in Montreal, Canada, co-editing with Klaus Brunnstein [12]. Back in 1988, when Harold Sackman began to champion and progress the development of an IFIP Code of Ethics, Berleur's WG9.2 was the obvious home for such a project, with much attention paid to how it might evolve at the regular Working Group meetings being held at Berleur's home institution, the University of Namur in Belgium. In 1996, Berleur and Brunnstein co-edited a book 'Ethics of Computing: Codes, Spaces for Discussion and Law' as a "Handbook prepared by the IFIP Ethics Task Group" among many other similar outputs that were published during the 1990s [6]. In 2004, at the end of his tenure at the helm of TC9, Berleur's sustained efforts produced the 'Criteria and Procedures for Developing Codes of Ethics or of Conduct' [8]. These criteria were applied in the creation of the Code of Ethics that IFIP adopted, finally, after 32 years of effort, at the 2020 General Assembly.

After Berleur, TC9's leadership moved decisively into the hands of WG9.4, with its former Chair, Chrisanthi Avgerou (2005-2010), moving into the TC9 Chair and then passing it to the South African representative Jackie Phahlamohlaka (2011-2013). By 2005 new working groups WG9.6, on IT Misuse and the Law (jointly with TC11), WG9.7 on History of Computing, and WG9.8 on Women and IT (now Gender, Diversity and ICT), had been formed, and Avgerou oversaw vigorous and enthusiastic chairing of all the Working Groups, revitalizing many of the WG's activities. Avgerou oversaw three Human Choice and Computers conferences: HCC7 in Maribor, Slovenia in September 2006, with the proceedings edited again by Berleur with Nurminen and Impagliazzo [9]; then in September 2008 HCC8 was held in Pretoria, South Africa with 
proceedings edited by Avgerou herself with Smith and van den Besselaar [1]; and finally HCC9 was held in Brisbane, Australia in September 2010 [10], as part of the World Computer Congress. HCC7 was notable for its memorial to Rob Kling and the proceedings focus on personal reflections as well as consideration to the impact of his body of work. Perhaps the most significant influence on the keywords from the HCC7 proceedings in contrast to previous conferences was the inclusion of Kling's name and the use of the term 'informatics' while many of the remaining words reflect the ongoing development of a critical thinking perspective across HCC scholarship (Figure 5). Phahlamohlaka then oversaw HCC10 in Amsterdam, Netherlands, September 2012, editing the proceedings with Herscheui, Whitehouse and McIver [18].

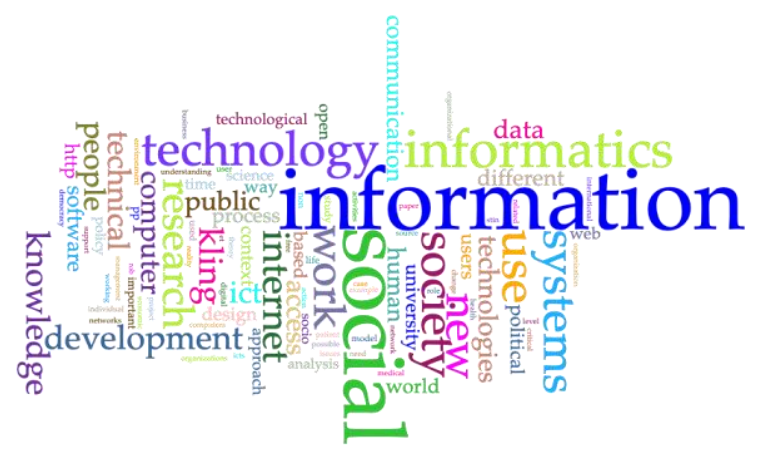

Fig. 5. HCC7 Keywords

Chairmanship of TC9 then passed back to the champions of ethics, firstly through former WG 9.2 chair, Diane Whitehouse (2014-2017) and then to the current chair, David Kreps (2018-current) who had joined WG9.5 in 2008 and became its Chair in 2013.

Whitehouse oversaw two HCCs: HCC11 in Turku, Finland, in July 2014, with the proceedings edited by Kimppa, Whitehouse, Kuusela and Phahlamohlaka [19]; and then HCC12 in Salford, Greater Manchester, UK, in September 2016 with the proceedings edited by Kreps, Fletcher and Griffiths [21]. Working Group 9.10 on ICT Uses in Peace and War was also formed and ratified at this time by Phahlamohlaka and Whitehouse. A belated recognition of the role of ICT in these contexts and acknowledgement of a strong South African team of academics dedicated to the topic.

Kreps, at the time of writing, has overseen three HCCs: HCC12 in 2016; HCC13 in 2018; HCC14 in 2020. He is now overseeing HCC15 for 2022. He has also led the publication of two key critical IFIP Papers.

At the General Assembly in Poznan, Poland, in 2018, Kreps championed the creation of an IFIP Position Paper on E-Waste [24]. This initiative was supported by members of the WG9.2 on Social Accountability and the reformulated WG9.9 on ICT and Sustainable Development. The statement was completed and published as a PDF report on the IFIP website in May 2019. 
At the IFIP General Assembly in Kiev, Ukraine, in 2019, Kreps then championed the creation and adoption of an IFIP Code of Ethics. A Task and Finish Group, chaired by Kreps, including the Chair of WG9.2.2 on Frameworks on Ethics of Computing, the Chair of IP $3^{1}$, and a representative from the Member Societies Assembly, worked through 2020 to finalize the new Code for its publication launch at IFIP's 60th Birthday Celebration - sadly postponed due to the global COVID-19 pandemic. Thirty-two years after Harold Sackman's stated ambition, nonetheless, the IFIP Code of Ethics has finally come to fruition, adopted by the General Assembly, published, and disseminated widely by IP3. It is also included in this volume.

As well as chairing HCC12, Kreps Chaired HCC13 as part of the World Computer Congress in September 2018 in Poznan, Poland sharing the editing duties of the proceedings with Ess, Leenen and Kimppa [22]. He then co-chaired HCC14 which was set to take place in Tokyo, Japan, in September 2020. However, these plans too fell foul of the pandemic and the Tokyo conference had to be cancelled. The proceedings were still produced with the editing completed by Kreps, Komukai, Gopal, and Ishii [25]. HCC15 in Tokyo is in preparation as this chapter goes to print, with editors Kreps, Davison, Komukai and Ishii. While the setbacks of the pandemic were an unexpected and external marker in TC9 and HCC's history, current indications of the significance of COVID-19's impact on the relationship of people and computing only serves to reinforce the ongoing importance of understanding this complex partnership, and the papers for HCC15 'Human Choice and Digital by Default: Autonomy vs Digital Determination' will no doubt reflect this.

\section{A Critical Perspective}

It is clear that what sets HCC and TC9 apart from other long-standing conference series that focus on information systems or people and technology is the critical perspective that has been its consistent hallmark.

As Avgerou says, in her personal history of her involvement with IFIP [3], "TC9 was, and perhaps continues to be, one of the very few international umbrella forums where the whole range of social issues can be discussed," but there are, today, a great number of specialist fora where academics can discuss and debate particular aspects of the social issues of computing, many of which include a strong critical voice (e.g. ETHICOMP, AoIR, 4S, EASST and others). TC9 - and its flagship conference HCC remains, however, in many respects both the original (since 1974), and the most widereaching and overarching forum for the critical perspective on ICT and Society, as some of its leaders' other publications underline [2, 23, 32]. This critical voice, moreover, brings philosophy into play underpinning its ethical stance [23, 35].

To explore this history, as stated in the introduction, the authors used a textual analysis tool to examine the existing corpus of HCC texts. Initial analysis focused on the prologues, introductions or key introductory chapters of each proceedings. These were

\footnotetext{
${ }^{1}$ IFIP's International Professional Practice Partnership
} 
analyzed for identifiable trends. HCC6 was not initially included as it could not be located through the UK's interlibrary loan system and HCC11 was not included due to its relatively brief prologue. Using optical character recognition to include the earlier conference introductions, the corpus was then processed through the voyant-tools website [40] to visualize the resulting trends. Figures $8-10,12$ were all produced in this way using solely the overview of the conference by the editors. After establishing the value of this approach, the entire text of all the conferences from HCC4 onwards - and including the HCC6 conference after obtaining a copy from the publishers - were converted to text and and again examined through the voyant-tools system. This complete corpus proved particularly useful for correspondence (Figures $5 \& 6$ ) and principal components analysis (Figure 3). Figures 1, 2, 5-7, 11, 13, 15 are all produced from the analysis of the full-text corpus while Figures 3 and 4 use the full text of just one of the proceedings. Exploration of the corpus for insight is only limited by the constraints of word count.

Correspondence analysis of the HCC corpus (from HCC4 onwards) reveals the consistency of themes over thirty-five years (Figure 6) with the specific proceedings being positioned relative to the focus and theme of each individual conference (Figure 7). The blend of people and computing is clearly evident with the specific identification of terms such as 'development', 'work', 'people and 'government' all providing indications of the underlying critical philosophy that informs this large body of work.

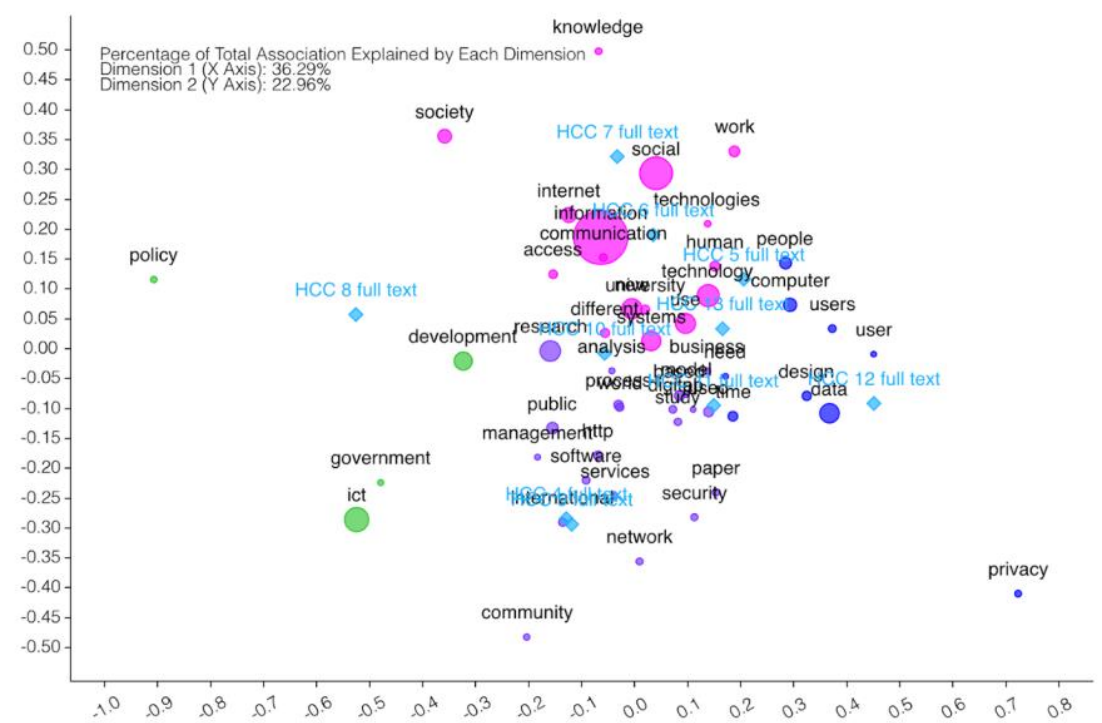

Fig. 6. Correspondence analysis of key terms in the HCC corpus (HCC4 to HCC13) 


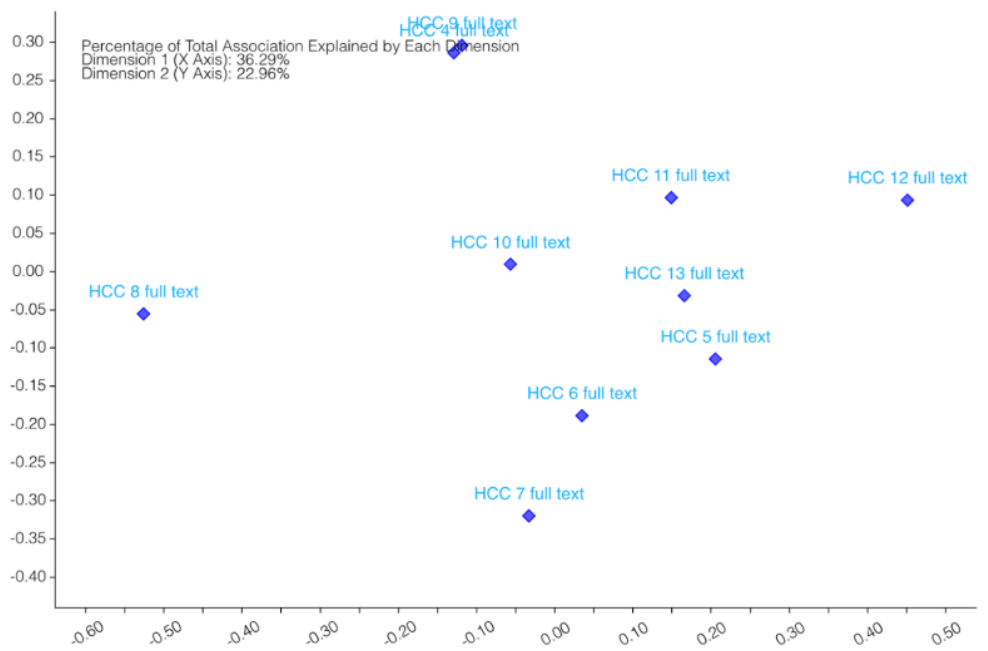

Fig. 7. Correspondence analysis of each HCC proceedings

Cecez-Kecmanovic [15] identifies critical information systems research as being defined by a socially critical point of view, or, as Klein and Myers put it, IS research "can be classified as critical if the main task is seen as being one of social critique, whereby the restrictive and alienating conditions of the status quo are brought to light" [20] This view is revealed in Sackman's 1986 list which places the objective most likely to initiate "transformative social change" [15] at the head of the list. Invariably this is reflected as an intertwining of 'social' and 'technology' across the corpus from HCC4. The most identifiable break in this relationship comes with HCC7 when the focus on Rob Kling's work and legacy briefly pushed the balance noticeably in favor of the social over that of technology (Figure 8). This is as strong an indication as any of Kling's own research emphasis in comparison to the underlying trend of other HCC conference contributors.

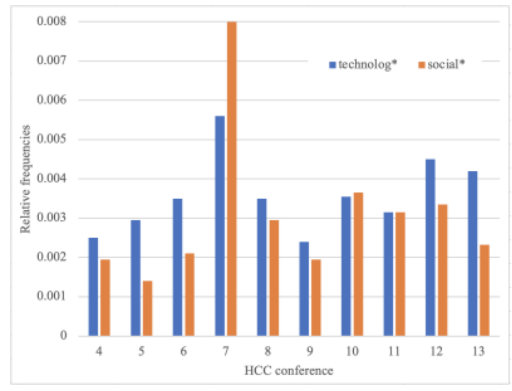

Fig. 8. The intertwined focus of technology and the social across the corpus of the full proceedings from $\mathrm{HCC} 4$ onwards

McGrath [27] confirmed the distinctiveness of HCC when she cited the proceedings of the first conference in 1974 as a watershed moment in the development of critical information systems thinking. The proceedings, she said, included an encouragement 
by editors Mumford and Sackman "to engage with the way that computer applications were being developed and deployed, and to make the human choices necessary to ensure that democratic values and ideals were preserved for the benefit of everyone" [27]. While Mumford and Sackman probably did not set out consciously to create this theoretical position, the critical focus and variety of challenges presented in the first conference were certainly a product of their time. An almost continuous concern with the position of labor, pressing union issues and the prevailing social theories of the time are peppered throughout the early proceedings of HCC.

\begin{abstract}
Worker orientation is also possible, and a lot should and will be done. From a certain point on, however, too much adaptation will result in overspecialization and this will rebound back onto the worker in the form of career and position difficulties. Flexibility is a human virtue and should be cultivated.[12]

Our subject, therefore, is a matter far beyond computer sciences. It has to do with sociology, psychology, physiology, with the art of management and government, with democratic decision making as well as legal decision making and even creation of law. It must deal with the large field of problems with which the trade unions are faced. And it extends even into philosophy and religion - if Europe and America do not teach this, Islam certainly does these days.[13]
\end{abstract}

The various threads of what are now recognizable as critical thinking in IS are developed more fully in later conference proceedings. In many cases, it is the small and offhand points made by earlier authors that became the pressing focus for later discussions. For example, Zemanek in 1979 [41] observed, "today we begin to realize how inseparable scientific and human development are." and Margulies' final footnote in 1979 [26] struggled with, "whether we could leave out home computers from our discussions or not - they will probably affect our attitudes towards computers and thereby affect our professional life." Margulies [26] started the first formalizing of the critical thinking perspective of HCC by provocatively entitling his contribution - in a rare moment of editorial reflexivity for any conference - as "Why 'HCC' again?" and by then stating:

\footnotetext{
...technology must not become an end in itself, but has to be seen in the context of man. Throughout history man has developed new means of production in his unceasing endeavor to make work easier and life better, thus at the same time creating new ways of human cooperation and societal organization. The technology of today also can only be justified by its service to man, by its contribution in improving the quality of life, in providing the chance of self-realization. [26]
}

In all of these early statements, with the benefit of hindsight, it is apparent that, with rapid evolution, adoption and popularization, information technology was pressing nearer and nearer and becoming ever more intimately tied with the human condition. 
In 1986 Sackman, working amidst the disruption of a fundamental ontological debate, identified major new forthcoming areas of concern for research that included - somewhat prophetically - "home information systems and social networking" and "robotics and artificial intelligence" [36]. While Barnes [4] is regarded as the originator of the term 'social network' this must be one of the first published instances of the term in relation to computers and information technology. This is an even more extraordinary statement when it is placed in the historical context of Dell Computers, the NSFNET (the first major TCP/IP network) and the WELL (the first digital community) all being only one year old in 1986.

With the increasing ubiquity and everyday presence of information technology, more recent HCC conferences have become less focused on work and more concerned with the general human situation including aspects of the personal and of the home (Figure 9). This does not mean the original concerns of HCC have now somehow disappeared but rather that they have now become supplemented and richer, to incorporate the fuller interplay of public and private (Figure 10) in ways that were not imagined or possible in the 1970 s or 1980 s.

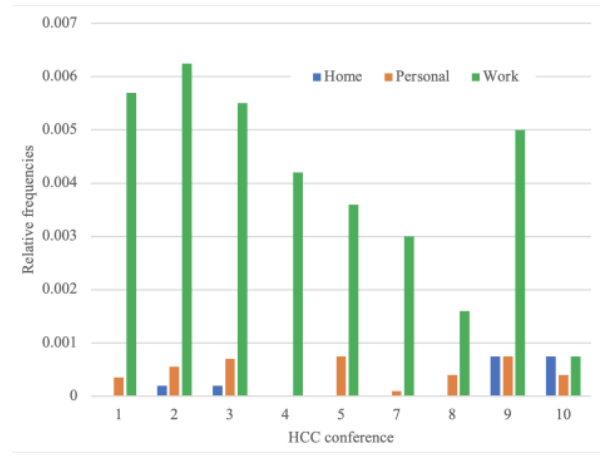

Fig. 9. Home and Personal vs Work through the HCC series.

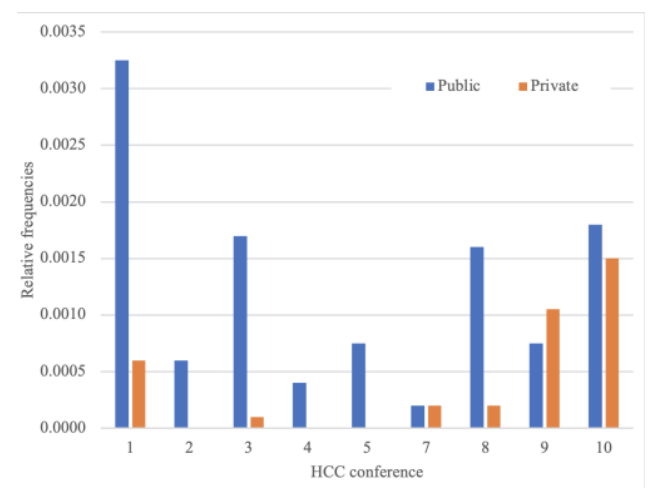

Fig. 10. Public vs Private through the HCC series. 
The spirit of HCC is consequently evident in the link tree of connected terms from the first HCC through to HCC10 held in 2012 (Fig. 11). The juxtaposition and mediating terms are themselves revealing of the intimate relationships between technology and people. "Information", "Human" and "Social" sit at the center of the diagram interlinking all the other concepts. Both "human systems" and "computer systems" are represented as is the classic "man machine" combination. "Human" and "Technology" are only sometimes mediated by the use of "policy" while "society", "technology" and "people" sit in a triangular relationship revealing an interdependence that is acknowledged by many HCC papers through the years. The entire corpus view of the linked terms from HCC 4 to HCC 13 reveal an even stronger trend (Figure 12). The six-way linkage of 'new', 'society', 'communication', 'economic', 'policy' and 'systems' predominates heavily and captures the root terms for so many of the recent HCC conference themes and concerns.

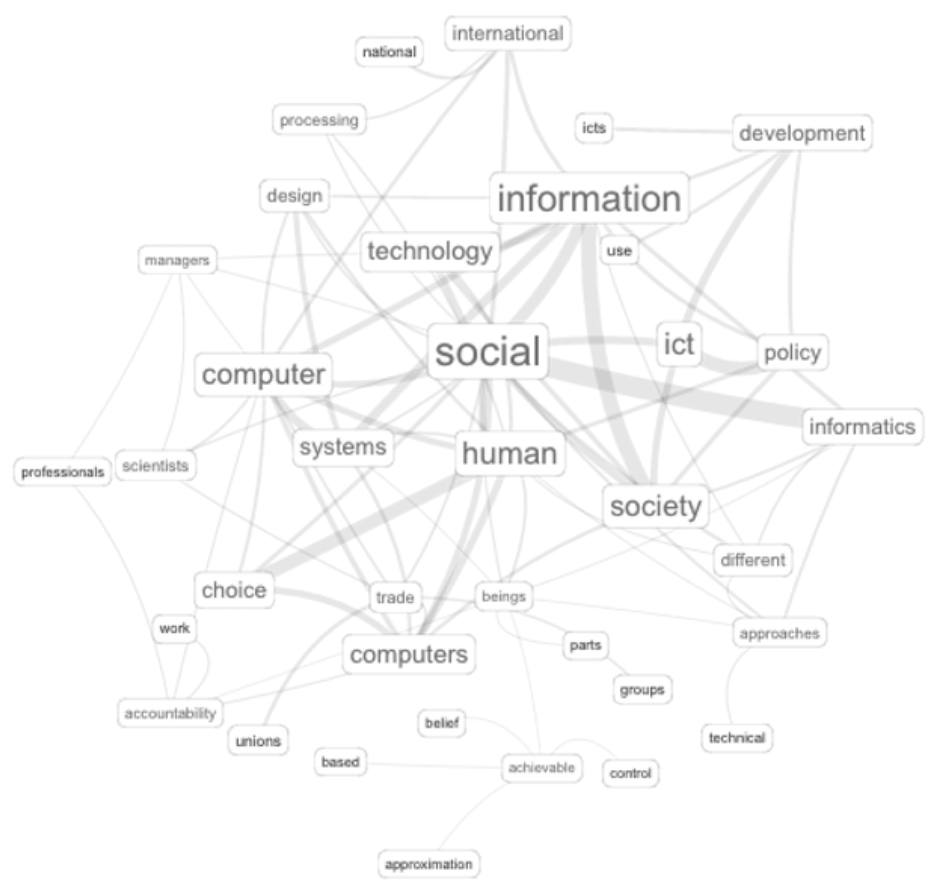

Fig. 11. Link tree of related terms generated from the HCC 1 to 10 introductory corpus. 


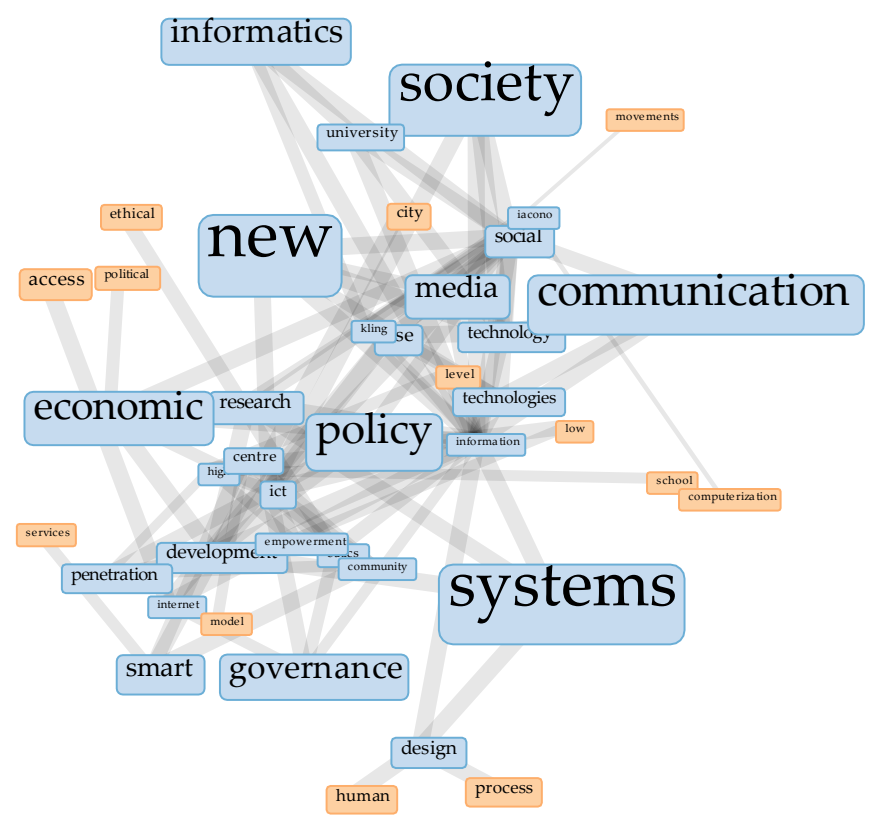

Fig. 12. Link tree of related terms generated from the full HCC4 to HCC 13 corpus

This fluctuating tension echoes the shifting personal emphasis of different TC9 chairs and the choice of conference themes across time appears to reflect a tension between the hardware-orientated concept of "computers" and the more central object in the relationship between technology and people in the form of "information" (Fig. 13). However, across the entire corpus it is clear that contributors to HCC are firmly focused on the role of information in their critical perspectives (Figure 14). With multiple devices constantly "near us" and "on us" (and soon "in us") the question of what any single computer is doing or how it will be deployed becomes less significant than what "we" will do with the consequent information that is being generated by the many devices now available for us to access, interpret and use. 


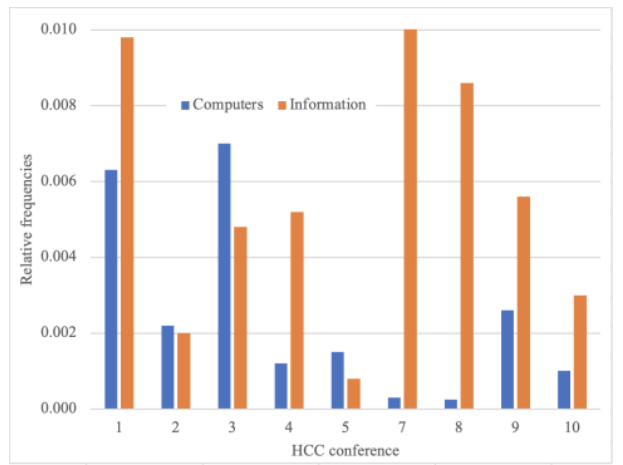

Fig. 13. Timeline of $\mathrm{HCC} 1$ to $\mathrm{HCC} 10$ proceedings with computers and information reflecting an editorial tension for focus

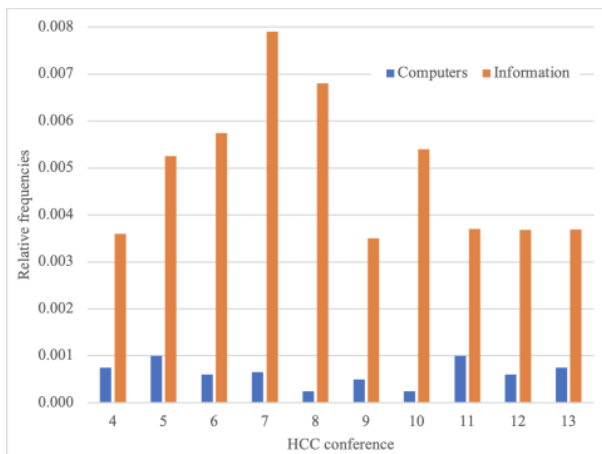

Fig. 14. Timeline of the full corpus of HCC4 to HCC13 with the unambiguous attention on information over computers.

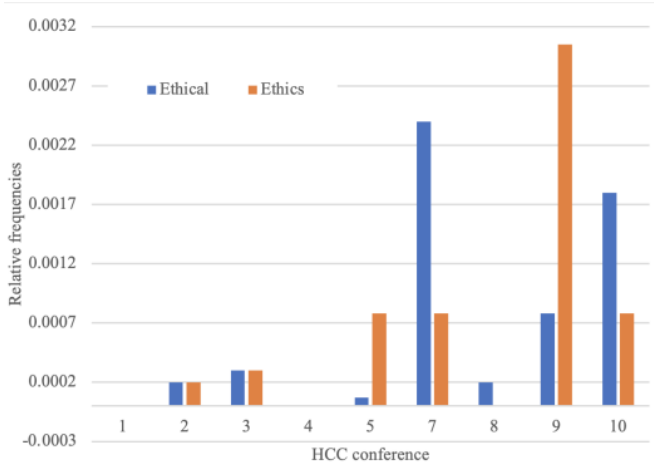

Fig. 15. The rise of ethical and ethics consideration in HCC introductions. 


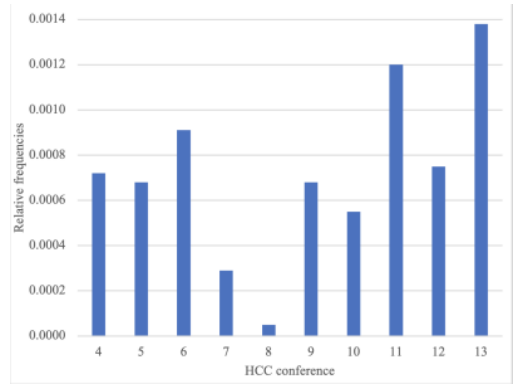

Fig. 16. The pace of the ethical turn across the full corpus of HCC4 to HCC13.

The predominance of 'information' across the full corpus of HCC papers also parallels an 'ethical' turn for the editors of each proceedings with rising attention commencing from HCC5 (Figure 15). This editorial trend can also be seen across the full corpus with a generally rising trend since HCC8 (where attention was more fully turned to different social issues) (Figure 16).

What Constantinides et al [16] might describe as progress towards the "ends" of Information Systems research. Perhaps, too, this 'turn' can be seen as expressing the gradual shift in the background of those involved in TC9 and HCC from predominantly computing engineers with social concerns, towards information systems academics whose principal background is the social sciences rather than computing [3]. The patterns of critical research, as Richardson and Robertson point out, seem broadly to have settled into a three-part format: insight, critique and transformative redefinition. Insight, "helps to highlight hidden or less obvious aspects of social reality;" critique, "challenges many of the taken-for-granted assumptions, beliefs, ideologies, discourses;" and transformative redefinition, "is the development of critical, relevant knowledge and practical understanding to facilitate emancipatory change" [34]. This ethical turn over the course of the HCC series, then, is in keeping with the transformative redefinition such critical research engenders. As people are brought into closer constant communication with technology the issues of ethics and the ethical boundaries between "what can be done" and "what should be done" becomes a more pressing and more evident challenge to researchers. As the number of interfaces increases so too do the ethical challenges.

\section{Conclusion}

As a long-standing conference series dedicated to critical information systems research, HCC has rightly stayed true to its heritage - and the overarching concerns of all those engaged in TC9 and working groups - by charting the increasing tension between the many possibilities that technology enables, in contrast to what "we" as a society should be doing with these capabilities. The personalities who, over the past decades, have championed these concerns, have all been fundamentally dedicated to these basic 
questions, whether focused more upon the ethics or upon those - whether socially marginalized in the developed world or located in developing countries - whose needs must not be forgotten, as new technologies evolve, and as our current era of digital determinism unfolds against the backdrop of anthropogenic climate change [23].

\section{References}

1. Avgerou, C., Smith, M. and van den Besselaar, P.: Human Choice and ICT Policy Policy: Introduction to the HCC8 Conference Proceedings. In Avgerou, C., Smith, M. and van den Besselaar, P. (eds) Social Dimensions of Information and Communication Technology Policy, Proceedings of the Eighth International Conference on Human Choice and Computers (HCC8), IFIP TC 9, Pretoria, South Africa, September 25-26, 2008. Springer. (2008).

2. Avgerou, C.: Information Systems in Developing Countries: A Critical Research Review. Journal of Information Technology 23(3), 133-146 (2008).

3. Avgerou, C.: IFIP TC9 Report: 1995-2010 - A personal account. In von Solms and Strous (eds.) 50 Years of IFIP. Springer, Heidelberg (2010).

4. Barnes, J. A.: Class and Committees in a Norwegian Island Parish. Human Relations 7(1), 39-58 (1954).

5. Beardon, C., Munari, S. and Rasmussen, L.: Prologue, In Rasmussen, L., Beardon, C. and Munari, S. (eds.) Computers and Networks in the Age of Globalization, Proceedings of the 5th IFIP-HCC (Human Choice and Computers) International Conference, HCC-5, Kluwer Academic Publishers, Boston. (2000).

6. Berleur, J. and Brunnstein, K.: Ethics of Computing http://www.ifip.org/36years/a53berlr.html (1996).

7. Berleur, J. \& Drumm, J. (eds.): Information Technology Assessment: Human Choice and Computers, 4, Proceedings of the Fourth IFIP-TC9 International Conference on Human Choice and Computers (HCC-4), Dublin, July 8-12, 1990, Elsevier, North-Holland, Amsterdam (1991).

8. Berleur, J., Duquenoy, P., Holvast, J., Jones, M., Kimppa, K., Sizer, R., Whitehouse, D.: Criteria and Procedures for Developing Codes of Ethics or of Conduct. On behalf of IFIPSIG9.2.2 IFIP Press, Laxenburg-Austria (2004).

9. Berleur, J., Nurminen, M., and lmpagliazzo, J. (eds.): Social Informatics: An Information Society for All? In Remembrance of Rob Kling, Proceedings of the Seventh International Conference on Human Choice and Computers (HCC7), IFIP TC 9, Maribor, Slovenia, September 21-23, (2006).

10. Berleur, J. Hercheui, M.D. and Hilty, L. M.: What Kind of Information Society? Introduction to the HCC9 Conference proceedings, In Berleur, J. Hercheui, M.D. and Hilty, L. M. (eds) What Kind of Information Society? Governance, Virtuality, Surveillance, Sustainability, Resilience. 9th IFIP TC 9 International Conference, HCC9 2010 and 1st IFIP TC 11 International Conference, CIP 2010. Held as Part of WCC 2010, Brisbane, Australia, September 20-23, (2010).

11. Bhatnagar, S.C., and Bjorn-Anderson, N. (eds.): Information Technology in Developing Countries. North-Holland, Amsterdam (1990).

12. Brunnstein, K. and Berleur, J. (eds): Human Choice and Computers, Issues of Choice and Quality of Life in the Information Society, Proceedings of the IFIP-TC9 HCC-6 Conference, 17th World Computer Congress, Montreal, August 2002, Kluwer Academic Publishers (2002). 
13. Bryant, T.: The Myth of Information Society, In Berleur, J. \& Drumm, J. (eds.): Information Technology Assessment: Human Choice and Computers, 4, Proceedings of the Fourth IFIPTC9 International Conference on Human Choice and Computers (HCC-4), Dublin, July 812, 1990, Elsevier, North-Holland, Amsterdam (1991).

14. CARO http://www.caro.org/index.html

15. Cecez-Kecmanovic, D.: Doing critical information systems research - arguments for a critical research methodology. European Journal of Information Systems 20(4), 440-455. (2011).

16. Constantinides, P., Chaisson, M. and Introna, L.: The Ends of Information System Research: a pragmatic framework. MIS Quarterly 36 (1), 1-19. (2012).

17. Gottlieb, C.: Computers - A Gift of Fire. Invited Presentation. In S.H. Lavington (ed.) Information Processing 80. North-Holland Publishing Company (1980).

18. Herscheui, M., Whitehouse, D., McIver, W., Phahlamohlaka, J., (eds.): ICT Critical Infrastructures and Society: 10th International Human Choice and Computers Conference, HCC10 2012, Amsterdam, The Netherlands, September 2012, Proceedings Springer, Heidelberg (2012).

19. Kimppa, K., Whitehouse, D., Kuusela, T., Phahlamohlaka, J. (eds.): ICT and Society: 11th IFIP TC9 International Conference on Human Choice and Computers, HCC11 2014. Turku, Finland, July 30 - Aug 1st, 2014, Proceedings. Cham, Switzerland: Springer International (2014).

20. Klein, H.K., and Myers, M.D.: A Set of Principles for Conducting and Evaluating Interpretive Field Studies in Information Systems. MIS Quarterly (23:1), 67-93. (1999).

21. Kreps, D., Fletcher, G., \& Griffiths, M., (Eds.): Technology and Intimacy: Choice or Coercion. 12th IFIP TC9 International Conference on Human Choice and Computers 2016, Salford, UK, September 7-9, 2016, Proceedings Cham, Switzerland: Springer International (2016).

22. Kreps, D., Ess, C., Leenen, L., \& Kimppa, K., (Eds.): This Changes Everything - ICT and Climate Change: What Can We Do? 13th IFIP TC 9 International Conference on Human Choice and Computers, HCC13 2018, Held at the 24th IFIP World Computer Congress, WCC 2018, Poznan, Poland, September 19-21, 2018, Proceedings Cham, Switzerland: Springer International (2018).

23. Kreps, D.: Against Nature: The Metaphysics of Information Systems. London, Routledge (2018).

24. Kreps, D., van der Velden, M., Fors, P., Patrignani, N., Davison, R., Lennerfors, T., Zielinski, C, Kasper, G.M. and Schultze, U,: IFIP Position Paper on E-Waste. Vienna, IFIP (2019).

25. Kreps, D., Komukai, T., Gopal, TV., Ishii, K., (Eds.): 14th IFIP TC9 Human Choice and Computers Conference: Human-Centric Computing in a Data-Driven Society HCC14 2020 Proceedings. Cham, Switzerland: Springer International (2020).

26. Margulies, F.: Why 'HCC' again? In Mowshowitz, A. (ed) Human Choice and Computers 2, Proceedings of the Second IFIP-TC9 Human Choice and Computers Conference (HCC2), Baden, Austria, 4-8 June, 1979, Elsevier, North-Holland, Amsterdam (1980).

27. McGrath, K.: Doing critical research in information systems: a case of theory and practice not informing each other. Information Systems Journal 15, 85-101 (2005).

28. Mowshowitz, A. (ed.): Human Choice and Computers 2, Proceedings of the 2nd IFIP-TC9 Human Choice and Computers Conference (HCC2), Baden (Austria), 4-8 June, 1979. Elsevier, North-Holland, Amsterdam (1980).

29. Mumford, E. \& Sackman, H.: International Human Choice and Computers: Conference Retrospect and Prospect, in Mumford, E. \& Sackman, H. (eds) Human Choice and Computers, 
Proceedings of the Conference on Human Choice and Computers (HCC-1), Vienna, Austria, April 1-5, 1974, Elsevier, North-Holland, Amsterdam (1975).

30. Mumford, E. \& Sackman, H. (eds): Human Choice and Computers, Proceedings of the Conference on Human Choice and Computers (HCC-1), Vienna, Austria, April 1-5, 1974, Elsevier, North-Holland, Amsterdam (1975).

31. Nurminen, M., Berleur, J. and lmpagliazzo, J.: Preface, in Social Information: An Information Society for All? In Remembrance of Rob Kling, Proceedings of the Seventh International Conference on Human Choice and Computers (HCC7), IFIP TC 9, Maribor, Slovenia, September 21-23 (2006).

32. Patrignani, N and Whitehouse, D.: Slow Tech and ICT. London, Palgrave (2018)

33. Rasmussen, L., Beardon, C. and Munari, S. (eds.): Computers and Networks in the Age of Globalization, Proceedings of the 5th IFIP-HCC (Human Choice and Computers) International Conference, Geneva, Switzerland, HCC-5, (August 25-28, 1998) Kluwer Academic Publishers, Boston (2000)

34. Richardson, H., and Robinson, B.: The mysterious case of the missing paradigm: a review of critical information systems research, Information Systems Journal, (17:3), 251-270. (2007).

35. Rowe, F.: Being critical is good, but better with philosophy! From digital transformation and values to the future of IS research. European Journal of Information Systems 27(3), 380393 (2018).

36. Sackman, H.: Historical Critique of IFIP TC 9: Computer Relationships with Society, In Sackman, H. (ed) Comparative Worldwide National Computer Policies, Proceedings of the 3rd IFIP-TC9 Conference on Human Choice and Computers, Stockholm (HCC-3), Sweden, 2-5 September 1985, Elsevier, North-Holland, Amsterdam (1986).

37. Indian Institute of Management Ahmedabad http://www.iimahd.ernet.in/ subhash/

38. Threat Radar 2015 https://www.virusradar.com/node/168

39. Virus Bulletin April 1996 https://www.virusbulletin.com/uploads/pdf/magazine/1996/199604-insight-KlausBrunnstein.pdf

40. Voyant-Tools http://www.voyant-tools.org/

41. Zemanek, H.: Human Choice - A subject of increasing general interest, In Mowshowitz, A. (ed) Human Choice and Computers 2, Proceedings of the Second IFIP-TC9 Human Choice and Computers Conference (HCC-2), Baden, Austria, 4-8 June, 1979, Elsevier, North-Holland, Amsterdam (1980). 